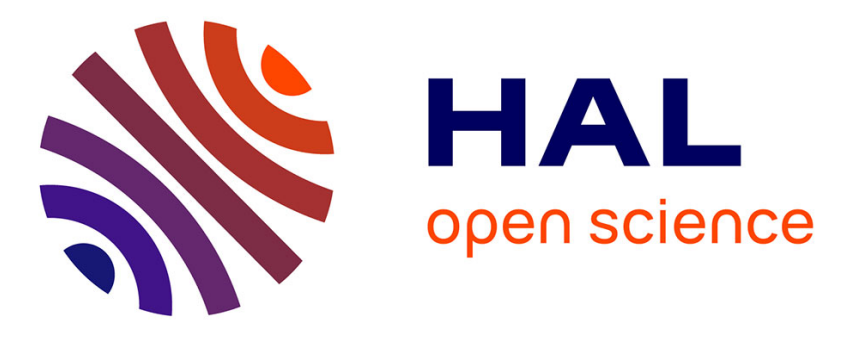

\title{
Multiple Cracks Interactions in Stress Corrosion Cracking: In Situ Observation by Digital Image Correlation and Phase Field Modeling
}

J Bolivar, Tt Nguyen, Y Shi, Marion Fregonese, Julien Réthoré, J Adrien, A King, Jy Buffiere, N Huin

\section{To cite this version:}

J Bolivar, Tt Nguyen, Y Shi, Marion Fregonese, Julien Réthoré, et al.. Multiple Cracks Interactions in Stress Corrosion Cracking: In Situ Observation by Digital Image Correlation and Phase Field Modeling. Environmental Degradation of Materials in Nuclear Power Systems, 2017, Portland, United States. pp.161-174, 10.1007/978-3-030-04639-2_10 . hal-01668875

\section{HAL Id: hal-01668875 https://hal.science/hal-01668875}

Submitted on 15 Jul 2021

HAL is a multi-disciplinary open access archive for the deposit and dissemination of scientific research documents, whether they are published or not. The documents may come from teaching and research institutions in France or abroad, or from public or private research centers.
L'archive ouverte pluridisciplinaire HAL, est destinée au dépôt et à la diffusion de documents scientifiques de niveau recherche, publiés ou non, émanant des établissements d'enseignement et de recherche français ou étrangers, des laboratoires publics ou privés. 


\title{
Multiple Cracks Interactions in Stress Corrosion Cracking: In Situ Observation by Digital Image Correlation and Phase Field Modeling
}

\author{
J. Bolivar, T.T. Nguyen, Y. Shi, M. Fregonese, J. Réthoré, J. Adrien,
}

\author{
A. King, J.Y. Buffiere and N. Huin
}

\begin{abstract}
Interactions between multiple stress corrosion cracks (M-SCC) have a major influence on crack growth but are underestimated in models devoted to the evaluation of the lifetime of industrial components. In this study, the growth and interactions between multiple cracks on a sensitized Alloy 600 in a $0.01 \mathrm{M}$ tetrathionate solution, were studied by digital image correlation (DIC). Cracks exceeding $55 \mu \mathrm{m}$ in length and $0.45 \mu \mathrm{m}$ in opening were successfully detected by DIC. The emergence and intensification of interactions modify the growth of the crack colony which evolves from a mostly surface crack propagation (lack of interactions) to in-depth propagation controlled by crack shielding. A multiphysics phase field model was jointly developed and successfully implemented to simulate intergranular M-SCC. It coupled a robust algorithm based on brittle fracture and a diffusion model. The resulting modeling allowed simulating the interactions between cracks and the shielding effects observed experimentally. Finally, 3-D quantification of crack propagation was performed by micro-tomography and digital volume correlation (DVC).
\end{abstract}

Keywords Stress corrosion cracking - Digital image correlation - Phase-field modeling · Micro-computed tomography

J. Bolivar $(\bowtie) \cdot$ Y. Shi $\cdot$ M. Fregonese $(\bowtie) \cdot$ J. Adrien $\cdot$ J.Y. Buffiere

Université de Lyon, INSA de Lyon, MATEIS UMR5510,

69621 Villeurbanne Cedex, France

e-mail: jose.bolivar-vina@insa-lyon.fr

M. Fregonese

e-mail: marion.fregonese @insa-lyon.fr

T.T. Nguyen · J. Réthoré

Université de Lyon, INSA de Lyon, LaMCoS UMR5259,

69621 Villeurbanne Cedex, France

A. King

Synchrotron SOLEIL, Psiche Beamline, 91190 Saint-Aubin, France

N. Huin

AREVA NP, Centre Technique, 71200 Le Creusot, France 


\section{Introduction}

The formation of stress corrosion cracks in engineering components often features multiple stress corrosion crack initiation, with growth and failure involving interaction and coalescence of those cracks. These steps can represent a significant fraction of a component's lifetime. This is the case, for example, of carbon steel pipelines which, in many instances, are affected on their outside surface by the development of "colonies" of intergranular or transgranular cracks. Examples of the development of such short cracks "colonies" on an Alloy 600 component exposed to Primary Water Reactor (PWR) environment have also been observed [1].

These aspects have been extensively studied for carbon steels for pipelines in carbonate-bicarbonate environments (see for example [2-7]). Figure 1 shows the successive stages of the life identified for a pipeline affected by SCC. In many cases, stages 2 and 3 can represent the major part of the pipeline lifetime since, during stage 3 , crack propagation rates are often about $100 \mu \mathrm{m} /$ year or less.

An important aspect of the evolution of crack colonies results from their interactions due to the modification of the stress-strain field in the vicinity of cracks with different effects: (i) a screening effect which slows down or even stops propagation (crack dormancy), (ii) a favored crack initiation near crack tips in zones of high stresses and strains (plastic zones) and finally (iii) crack coalescence which may lead the formation of long cracks whose stress intensity factor can exceed the critical value for fast propagation (stage 4 in Fig. 1).

Parkins et al. [3] have shown that in carbon steels and C-Mn steels, the interaction of cracks is mainly controlled by the separation $h$ between the parallel crack path and the length $\left(2 a_{1}\right.$ and $\left.2 a_{2}\right)$ of two neighboring cracks, i.e. coalescence occurs

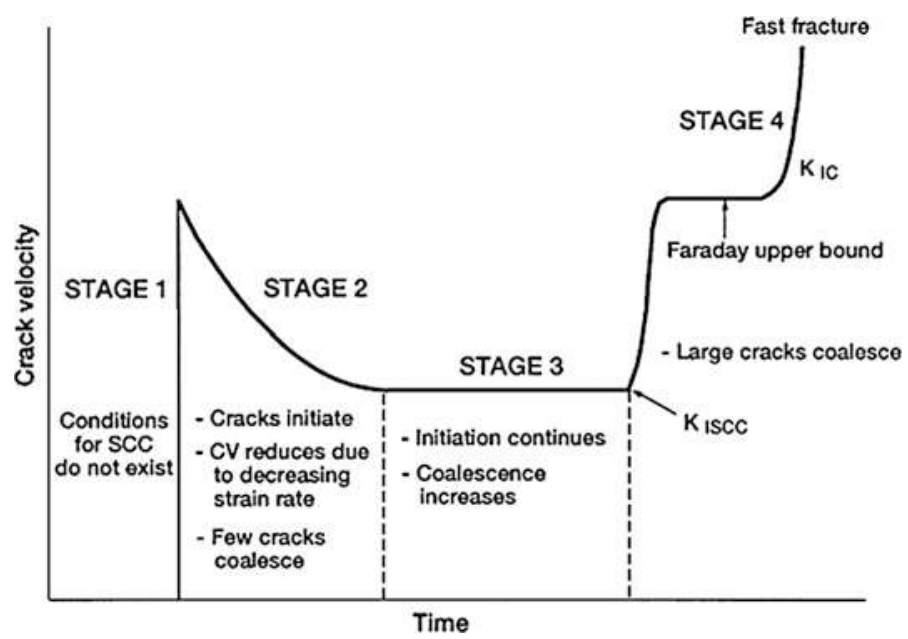

Fig. 1 Multiple stress corrosion cracks initiation, coalescence, and growth on pipeline steels according to (Reproduced from Parkins [2]) 
when $h<0.14\left(a_{1}+a_{2}\right)$. This criterion is similar to the criterion found experimentally for coalescence of fatigue cracks [8] which means that at least for the systems studied by Parkins et al. [2-7], the interaction between cracks is a purely mechanical process. The same criterion has been experimentally derived by Calonne et al. [9] for Alloy 600 exposed to primary water. This criterion has been explained qualitatively by the overlapping of the plastic zones of two neighboring cracks [10].

Since the stress-strain field around crack tips plays a key role in crack interactions, the use of digital image correlation (DIC) which is an optical technique designed to measure full displacement fields and/or full deformation fields in solids [11] may bring significant insight on this process. Indeed, DIC has been widely used in the fracture mechanics field due to its simplicity and high-resolution capabilities [12-15]. The basis of DIC technique involves capturing successive images of the surface both before (reference image) and after deformation. Comparing these images allows estimating displacement fields [16]. In order to facilitate the comparison, the surface of the studied object must display a random pattern (non-repetitive, isotropic and with high contrast) [17], which is generally obtained by spraying black and white paints [11]. When the application of a paint is not possible (e.g. corrosive media, high temperatures) [18], the surface preparation can be performed by abrasion or metallographic attacks [19].

Several studies have already used DIC on atmospheric SCC of Type 304 stainless steels [20] and on SCC of sensitized type 304 in tetrathionate solutions [21] and thiosulfate solutions [22]. In this last case, DIC was coupled with acoustic emission (AE) and electrochemical noise (EN) in order to improve the analysis of the cracking process. DIC was also used to observe the propagation of short cracks in sensitized Type 304 stainless steel in high temperature water [23, 24].

This technique has recently been extended to the 3D characterization of strain fields, consisting in digital volume correlation (DVC, i.e. 3D-DIC), on microstructures exhibiting X-ray contrast that can act as a natural 3D pattern (e.g. $\mathrm{Cu}$ intermetallics in an $\mathrm{Al}$ matrix, spheroidal graphite in a cast iron [25-27]). DVC can be carried out from tomography images that allow reconstructing the volume of the damaged specimen and high resolution can be reached by using synchrotron radiation [28]. Actually, synchrotron tomography enables to work with phase contrast (electron density related), that enhances the quality of the images of heterogeneous materials, showing phases with very similar attenuation coefficients (absorption contrast) [29]. In addition, it also improves the imaging of cracks with a sub-voxel opening [30, 31].

In this context, the present work aims at identifying and modeling the different stages of the evolution of an intergranular stress corrosion cracks colony. Firstly, 2D-DIC technique has been used to characterize the individual evolution of each crack of the colony and to discuss the mechanisms involved in each stage. Simultaneously, a new multiphysics model based on the phase field method has been developed in order to simulate the observed crack evolutions. Direct comparisons between the simulated crack paths and experimental data are performed, and a strategy is proposed to identify the parameters of the constitutive model by 
using the DIC results. Finally, in situ micro-tomography and DVC are carried out in order to validate the $2 \mathrm{D}$ experimental approach and the results of the $3 \mathrm{D}$ phase-field modeling.

\section{Experimental Procedures}

Initiation and growth of multiple stress corrosion cracks were obtained by testing $2 \mathrm{~mm}$ thick tensile specimen of fully sensitized $\left(30 \mathrm{~h}\right.$ at $600{ }^{\circ} \mathrm{C}$ and air-cooled) Alloy 600 (composition in Table 1) in a $0.01 \mathrm{M}$ potassium tetrathionate solution acidified by $\mathrm{H}_{2} \mathrm{SO}_{4}$ addition at room temperature. The grain size of the material was $70-110 \mu \mathrm{m}$. Prior to testing, the sample surfaces dedicated to 2D-DIC analysis were grinded using SiC papers to 1200 grit, and then electro-etched in a solution of $8 \%$ perchloric acid and $92 \%$ acetic acid $(5 \mathrm{~V}$ for $30 \mathrm{~s}+10 \mathrm{~V}$ for $1 \mathrm{~min})$. This surface treatment produces a mixed micro and macro shallow pattern, suitable for further 2D-DIC analysis.

Details of the experimental procedure (constant load SCC tests) on the 2D-DIC analysis of the crack colony are given in [32]. It can be summarized as follows: $7 \times 8 \mathrm{~mm}^{2}$ DIC analyzed surface area, DIC examination every $10 \mathrm{~min}$, subpixel resolution $(1 \mathrm{px}=3.45 \mu \mathrm{m})$.

Moreover, DVC analysis was carried out from micro-tomography images that were obtained using a specific SCC device (Fig. 2). In situ SCC experiments were performed on Psiche beamline at Synchrotron SOLEIL. The experimental device consisted of a miniaturized tensile machine equipped with a Perspex cell. The latter contained the test solution and allowed both electrochemical measurements and load control.

A three-electrode cell configuration was used for performing the experiments. The tensile specimen was used as the working electrode (WE), a saturated calomel electrode (SCE) was used as a reference and a Pt wire as the counter electrode (CE). Both the SCE as well as the CE were placed in the upper part of the cell so that they do not interact with the X-ray beam (Fig. 2b). Metallic parts of the cell were protected by a varnish in order to avoid any galvanic coupling. SCC initiation and propagation were obtained by the simultaneous application of suitable electrochemical potential and tensile stress.

The tensile stress was applied using a constant strain rate of $1.25 \times 10^{-4} \mathrm{~s}^{-1}$ until achieving the targeted load. Scans were performed during deformation from 0 to $140 \%$ of yield stress (YS), every $45^{\prime}$ approximately. During each scan, the displacement was stopped, and a cathodic potential (-300 mV/SCE) was applied to

Table 1 Chemical composition (\%wt.) of the studied Nickel based Alloy 600

\begin{tabular}{l|l|l|l|l|l|l|l|l|l|l}
\hline Alloy 600 & $\mathrm{Ni}$ & $\mathrm{Cr}$ & $\mathrm{Fe}$ & $\mathrm{Ti}+\mathrm{Al}$ & $\mathrm{Mn}$ & $\mathrm{Si}$ & $\mathrm{Co}$ & $\mathrm{Cu}$ & $\mathrm{C}$ & $\mathrm{S}$ \\
\hline & 74.5 & 15.5 & 9.250 & 0.25 & 0.12 & 0.15 & 0.10 & 0.10 & 0.030 & 0.002 \\
\hline
\end{tabular}


(a)
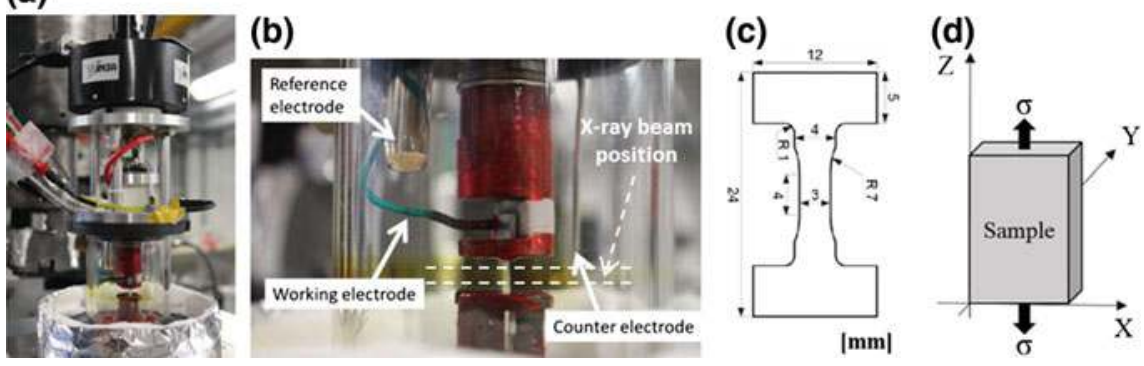

Fig. 2 Experimental device: a General view, b Disposition of the electrodes, c Sample geometry (gauge size: $3 \times 4 \mathrm{~mm}^{2}$ ), d Spatial reference system for tomography analysis

stop anodic dissolution and crack growth. Images were obtained in pink beam mode $(\mathrm{E}=80 \mathrm{keV})$ on a Hamamatsu Detector $(2048 \times 2048$ pixels $)$. The scan duration was about 5 min (1020 images averaged of 10 radiographs for each, exposure time of $25 \mathrm{~ms}$ ) with a $2.34 \mu \mathrm{m}$ voxel size. DVC analysis was performed taking into account the whole cross-section of the sample $(2950 \times 1100 \mu \mathrm{m})$ and $950 \mu \mathrm{m}$ of the gauge length. In order to accelerate the formation of crack colonies, DVC experimental conditions were different from the one adopted for 2D-DIC analysis [32] (increasing constant load steps from $120 \%$ up to $140 \%$ YS at pH 4 vs. constant load at $80 \%$ YS and pH 3, respectively). Yet, stress corrosion cracks colonies exhibited very similar crack density and morphology in both cases.

\section{Experimental Results and Discussion}

\section{D Analysis of the Stress Corrosion Cracks Colony}

The in situ experimental configuration that was designed for the study by 2D-DIC of the behavior of multiple stress corrosion cracks [32] allows obtaining intergranular crack colonies with a very brittle aspect and low levels of plastic strain (Fig. 3a).

An in-house data treatment routine was specially developed for the identification, classification, and monitoring of cracks. Cracks exceeding $55 \mu \mathrm{m}$ in length and $0.45 \mu \mathrm{m}$ in opening were detected. Crack population was classified into initiating, active and dormant cracks and the evolution with time of each population was obtained (see [32] for details of the criteria of the classification). Crack interactions such as coalescence and shielding were also identified. In addition, from the measurement of the length $(2 c)$ and the widest opening of the crack $(a)$, an aspect ratio $\eta=d / c$ ( $d$ : crack depth; $c$ : half-length) was calculated using Eq. 1 [33]. This aspect ratio allows describing the evolution in time of the crack shape and also the impact of the intensification of interactions on crack propagation, i.e. a 
(a)

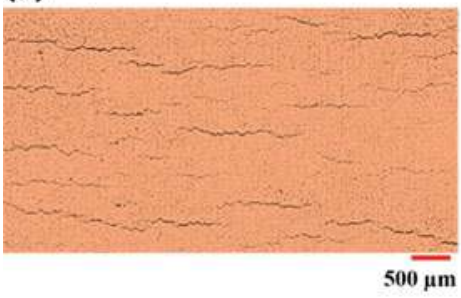

(b)

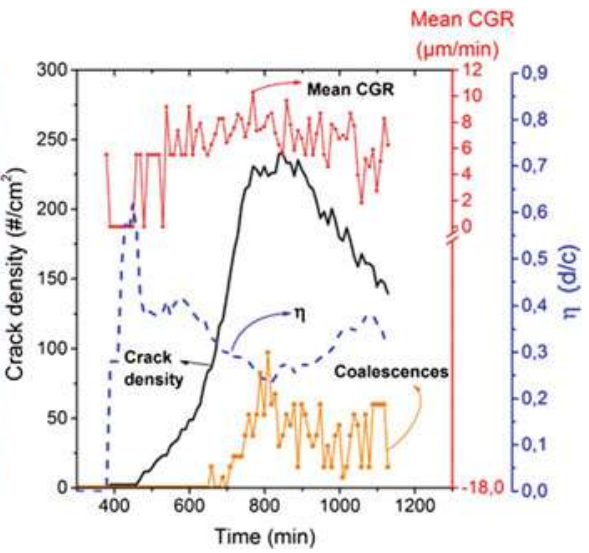

Fig. 3 Typical results for the SCC experiments performed on a sensitized alloy 600 tested in $0.01 \mathrm{M} \mathrm{K}_{2} \mathrm{~S}_{4} \mathrm{O}_{6}$ at $\mathrm{pH} 3$ (room temperature, $80 \% \mathrm{YS}$ ). a Typical morphology of the obtained crack colony and $\mathbf{b}$ description of the evolution of the crack colony through several crack descriptors (the average value of $\eta$ for the whole population of cracks is reported here)

decreasing " $\eta$ " indicates faster surface propagation, while an increasing " $~ \eta$ " is the indication of a faster in depth propagation [33].

$$
\frac{a}{c}-\left(\frac{d}{c}\right)\left[4 \sqrt{2}\left(1-v^{2}\right)\left(\frac{\sigma}{E}\right)\left(1+0.12\left(1-\frac{d}{c}\right)\left(\sqrt{1-0.619 \frac{d}{c}}\right)\right]=0\right.
$$

The terms $\sigma, v$ and $E$ represent the loading stress, the Poisson's ratio and Young's modulus of Allow 600 (obtained from literature) respectively. A typical evolution of the crack colony, using the above descriptors is depicted in Fig. $3 \mathrm{~b}$. The joint evolution of the different crack descriptors (populations, mean aspect ratio, and mean crack growth rate (CGR, determined as the mean of the differences in length $(2 c)$ between two successive acquisitions over the elapsed time for each crack), together with the complementary AE and EN measurements, allows identifying three stages of cracks development. (i) in the first part of the test active dissolution, and lack of re-passivation were responsible for crack advance, which remained at the surface and involved very few interactions; (ii) in the second stage, interactions between cracks (coalescence + shielding) began to occur but did not modify the general behavior of the colony, whose growth remained mainly controlled by active anodic dissolution; (iii) subsequently, the intensification of interactions led to a decrease in the number of active cracks and the crack growth rate and mechanics finally became the main driving force for crack propagation which principally affected crack depth. 


\section{Phase Field Modeling from 2D Experimental Data}

For modeling the development of the cracks colony, a phase field approach based on brittle failure was developed. The mechanical part of the model was based on the work by Nguyen et al. [34]. The phase field method developed in this work was based on the following points: (i) a separation of the strain energy density in a positive part (driving damage) and a negative part. The positive part was computed from the positive Eigen values of the strain tensor only whereas the negative part of the energy derives from the negative Eigen values and (ii) a history dependent variable was introduced in the formulation to account for the irreversibility of the damage process. This recast the global minimization problem to solve sequentially two linear problems, one for the balance of momentum and one for damage evolution.

In addition to elastic parameters, this model involved a failure energy $g_{c}$ and an internal length $l_{c}$. The influence of corrosion was accounted through the concept of diffusing degradation denoted $C$. The surface failure energy $g_{c}$ was supposed to be a decreasing function of $C$. The diffusing degradation was varied between 0 and 1 , " 1 " meaning maximum degradation. A unit value was thus prescribed by $C$ at the crack front, and its variation was assumed to be governed by a process which can be described by a diffusion law. This was modeled by a classical diffusion equation involving a conductivity parameter. This parameter was taken as a decreasing function of the distance to the specimen surface, in order to reproduce a crack propagation faster at the surface than in depth. The diffusion equation was solved prior to the balance of momentum and damage evolution. All these equations were solved using finite elements. The details of the equations and their resolution are given in [35].

In order to compare with experimental results, a sub-domain of the zone analyzed by 2D-DIC was modeled. The measured displacement field was applied on the boundary of this domain as boundary conditions. Crack initiation was actually dictated by defects in the microstructure. The model did not include this ingredient, but the analysis of the measured displacement fields allowed detecting where and when new crack initiate at the surface. This information was introduced in the model by modifying the history function where and when crack initiation was observed. Then the evolution of damage was solved in 3D to predict the behavior of the cracks colony. The proposed model was purely phenomenological, but it was shown to be robust and predictive for crack propagation and crack interactions as illustrated in Fig. 4.

\section{DVC Analysis of the Stress Corrosion Cracks Colony}

In situ high-resolution X-ray synchrotron tomography was performed to determine the $3 \mathrm{D}$ shape of the cracks (of the colony). The latter would allow (i) validating the 
(a)

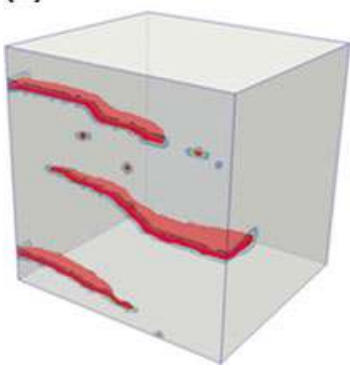

(b)

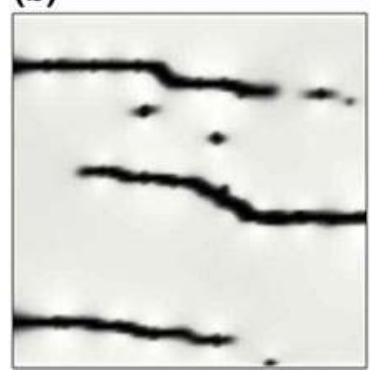

(c)

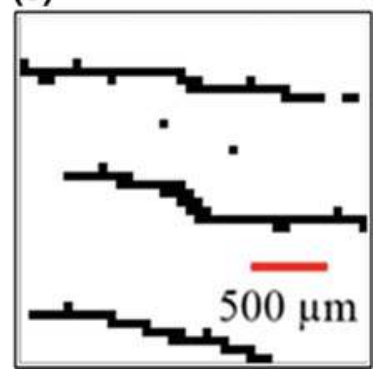

Fig. 4 Simulation over a sub-volume of the propagation of a cracks colony, a 3D view of the sub-volume, b Surface view, simulation, c Surface view, experimental data

results obtained from bi-dimensional data (2D-DIC), (ii) estimating stress intensity factor values from 2D measurements (2D-DIC) and (iii) validating the numerical results of a future model (considering 3D experimental data).

In fact, reconstructed tomographic images of the Alloy 600 revealed the existence of both gray levels distribution and phase contrast due to the presence of titanium nitride precipitates, which allow performing DVC with an accuracy that was sufficient for the convergence of the analysis. DVC was used to calculate the correlation error field from which the crack morphology can be extracted. The segmentation process of the cracks from the error field was actually much easier and more rapid than from the tomography images.

\section{Validation of 2D Measurements}

The error field obtained from the DVC analysis allowed the 3D shape of the cracks to be identified and extracted. The extraction of crack dimensions was performed using an in-house developed MatLab routine. The extraction method is based on enclosing each crack with the smallest possible bounding box (Fig. 5). Crack depth was defined as the depth of the bounding box, and crack length as the diagonal of the face of the bounding box containing the crack mouth (Fig. 5). Finally, the opening was defined as the maximum value of the opening of the outer surface of the crack. This allowed calculation of the aspect factor " $\eta$ " from direct measurements of crack depth instead of using an analytical estimation in the 2D previous approach (see Eq. 1 in Section "2D Analysis of the Stress Corrosion Cracks Colony").

Figure 5 displays the evolution of the mean value of $\eta$ (determined for each crack then averaged) during the in situ micro-tomography SCC experiment. The aspect factor decreases during the first part of the test, then remains almost constant during a period of about $200 \mathrm{~min}$ of test, and then finally increases in the last part of the test. In this context, the results presented just above validate trends observed through 2D-DIC (Section "2D Analysis of the Stress Corrosion Cracks Colony"). 


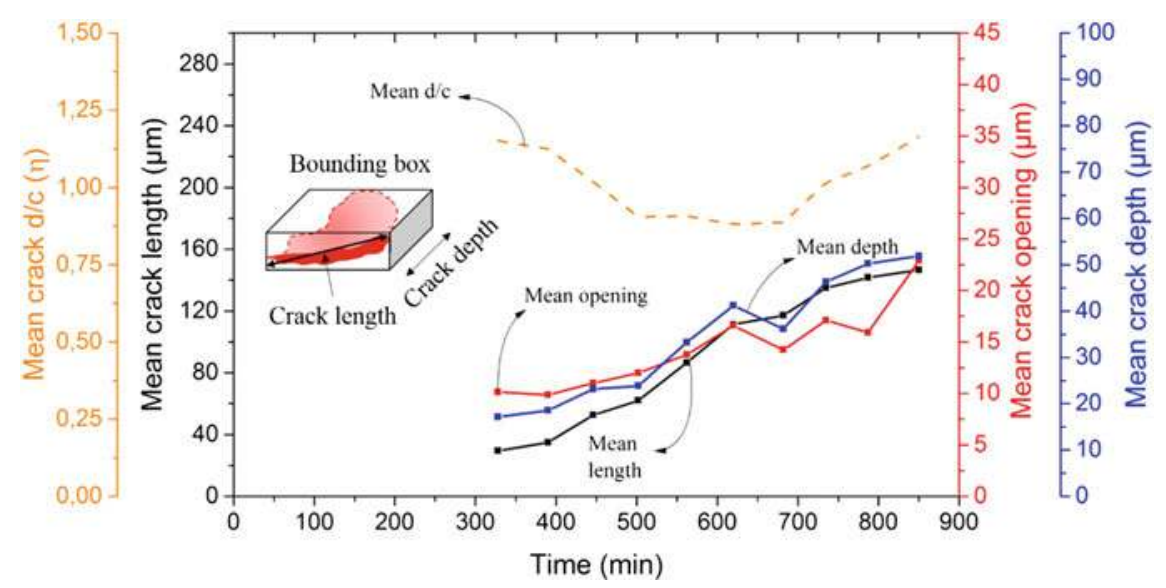

Fig. 5 Evolution of the mean dimensions of the SCC cracks (length, opening, and depth, determined for each crack, then averaged) detected on a sensitized alloy 600 tested in a solution of $0.01 \mathrm{M} \mathrm{K}_{2} \mathrm{~S}_{4} \mathrm{O}_{6}$ at $\mathrm{pH} 4$ (room temperature, $120-140 \% \mathrm{YS}$ )

The same both first decrease and last increase stages of $\eta$ were observed. In between, a constant $\eta$ stage was identified, which can be associated to a phase during which the interactions between the cracks do not significantly influence the propagation of the colony. It is possible that the crack opening is wide enough to facilitate the anodic process responsible for the crack tip propagation. Such hypothesis could explain why the cracks propagate both at the surface and inside the material during this stage.

\section{Shape of the Intergranular Stress Corrosion Cracks}

The morphology of the cracks was evaluated in a qualitative manner directly from the reconstructed tomography images. Figure 6 depicts the aspect of a representative crack (here named "I") for three successive scans, starting from 620 min until $840 \mathrm{~min}$ for the last scan (i.e. covering the end of the second propagation stage and the third one). The first row of the images represents the reconstructed tomography slices belonging to the sample surface. The second row, displays the projections of the slices of the plane parallel to the surface of the sample, with respect to the Y-axis (see Fig. 2d). Finally, the third row represents the projection of the slices perpendicular to the crack plane (with respect to the Z-axis). The projections depicted on both the second and third rows allow observing the extension of the crack propagation inside the material.

The first important result for the modeling approach is that cracks tend to maintain a semi-elliptical form as exhibited by the crack "I"; which was relatively isolated within the colony (last row in Fig. 6). However, due to the intergranular character of the cracking, cracks paths are very tortuous and exhibits deviations 

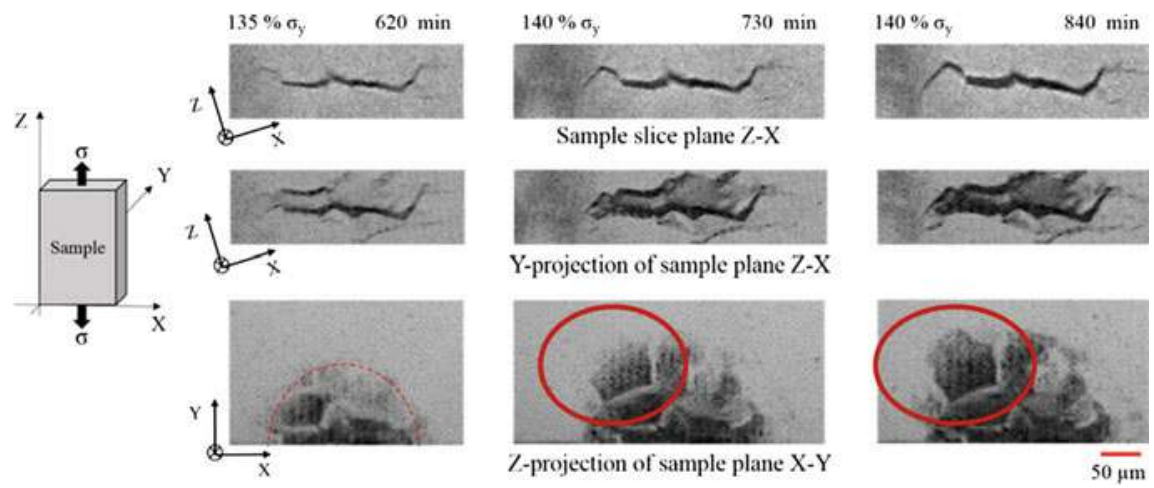

Fig. 6 Morphology of the crack referred as "I" in the text. Red ovals shows preferential propagation on a single grain boundary (Color figure online)

from their principal propagation plane as well as "fingerprints" which are believed to occur when crack moves to different grain boundary. Similarly, crack shape differ from a perfect semi-ellipse, due to the influence of microstructural features on the propagation mechanisms, such as triple points, special grain orientations, grain boundary energy, internal stresses, second phases ... Such effect appears on the Z-projection showed on Fig. 6 (last row), where it can be observed that, between 730 and $840 \mathrm{~min}$, the crack front grew preferentially over a large grain boundary plane (inside red ovals on last row of Fig. 6) with less microstructural obstacle.

Moreover, according to Fig. 6, crack "I" exhibited almost no surface propagation during the period displayed (620-840 min), while both the opening and the depth dimension of the crack increased. The images presented in this figure correspond to the period (620-840 $\mathrm{min}$ ) were mean aspect factor $\eta$ increases (Fig. 5). As already mentioned, during this stage, the crack is strongly shielded by its neighbors. This shielding appears to be more efficient on the surface and seems to lead to higher stress intensity at the deepest point of the crack rather than on the surface, thus promoting in-depth growth.

Regarding the coalescence process, it was very often observed that some very closely neighboring cracks, which seems to be discontinuous on the outer surface of the sample, indeed have started to coalesce inside the material. This can be evidenced in Fig. 7 (at $730 \mathrm{~min}$ ); it can be noticed that the two cracks on the right are not connected when viewed from the surface of the sample, nevertheless, on the images corresponding to the Y-projection (second row), the dark zone across the remaining ligament between the two cracks means that, in fact, the cracks did not merge in the surface, but they started to do it inside the material. Recent studies have already reported this kind of feature for both transgranular and intergranular SCC, in single or polycrystalline materials [36-38], suggesting that the process is characteristic of an SCC phenomenon. 


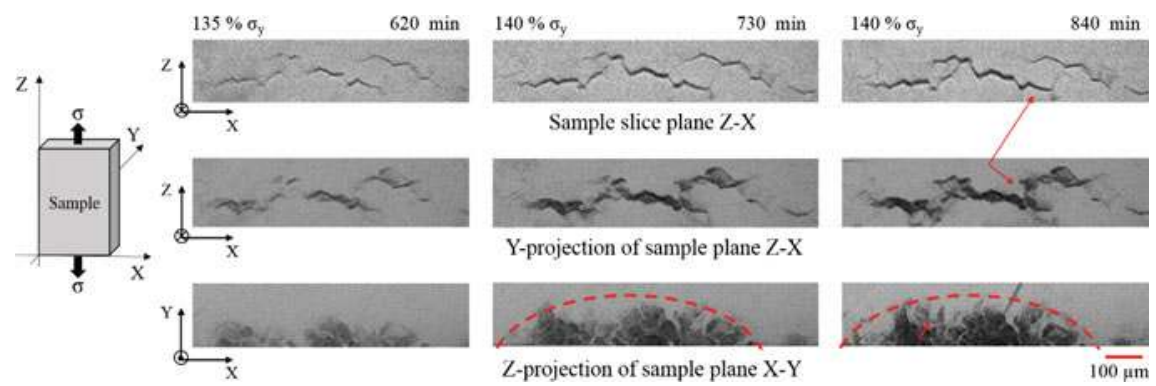

Fig. 7 Morphology of the crack "II" showing that sometimes crack coalescence may start in-depth rather than in surface (see red arrows)(Color figure online)

Figure 7 also shows how the semi-elliptical shape of the cracks changes due to a coalescence event. The final defect results from the coalescence between five cracks (see Fig. 7 at $620 \mathrm{~min}$ ). The resulting crack front during the coalescence is not "semi-elliptical" anymore (at $620 \mathrm{~min}$ ). Nevertheless, the pictures on the third row of Fig. 7 suggest that there exists a tendency to return close to a semi-elliptical form as the cracks propagate.

Above-mentioned experimental observations are of great significance for validating the proposed model in Part 3.2. Indeed, the semi-elliptical shape of the cracks obtained by phase field modeling agrees very well with the experimental observations, even in the cases when the propagation of the defect can be influenced by the miscrostructure. Nevertheless, it was observed that some discontinuous surface cracks were actually continuous within the sample. This phenomenon is believed to be caused in some cases by "crack branching" and in other cases by the crack tip deviation during the coalescence event [39]. Both processes are known by producing remaining ligaments between both interacting cracks; the process is very often called "crack bridging" [40]. Regarding the internal coalescence, the authors believe that once the bridge form, both interacting cracks propagate inside the material (Fig. 7, $620 \mathrm{~min}$ ). The merging of the inner crack tips is restricted because of the shielding effects between both cracks. Nevertheless, it can also be limited by microstructural factors (e.g. resistant grains). If the interacting cracks are located in a dense crack colony (as is the case here), the existence of multiple cracks would generate a significant relaxation of the stress on the surface, hence increase the driving force on the deepest crack tips and promote the internal coalescence.

Moreover, crack bridging can have important effects on crack growth. In fact, the existence of a remaining uncracked ligament inside a crack reduces the effective crack driving force, hence slow down the propagation of the crack [36, 39, 40]. The experimental observation detailed here has allowed identifying critical aspects that should be taken into account in the proposed model in order to better describe the SCC phenomenon. 


\section{Conclusions}

Based on a joined experimental and numerical approach, the present work allowed identifying and modeling the different stages of the evolution of an intergranular SCC colony.

Thanks to the use of a 2D-DIC technique, the individual evolution of each crack of the colony was characterized and the mechanisms involved in each stage were identified. In the first stage of development, active dissolution and lack of re-passivation are responsible for crack advance, which remains at the surface and involves very few interactions; in the second stage, interactions between cracks (coalescence + shielding) begin to occur but don't modify the general behavior of the colony, whose growth remains mainly governed by active anodic dissolution; finally, the intensification of interactions leads to a decrease in both the number of cracks and the mean crack growth rate.

These preliminary experimental results provided boundary limit conditions for the phase-field modeling that was developed in order to simulate the observed crack evolutions. A remarkable agreement between the simulation and the experimental results in $2 \mathrm{D}$ was obtained.

Complementary 3D experimental approach involving in situ micro-tomography SCC tests and digital volume correlation finally validated (i) the closed-semi-elliptical shape of the cracks, (ii) the different stages of the crack colony growth and (iii) the 3D predictions of the phase-field modeling.

Acknowledgements The authors would like to acknowledge the National French Research Agency (ANR) for its financial support under contract MATETPRO ANR-12-RMNP-0020 (ECCOFIC project). The authors are also grateful for the beam time awarded by synchrotron SOLEIL on the Psiche beamline (20140951 and 20150856 accepted proposals) and acknowledge warmly the technical and scientific support they benefited. The authors would like also to thank their partners: Institut de la Corrosion, Andra, MISTRAS Group and Pierre Combrade for their participation in the fruitful discussions during this work.

\section{References}

1. J. Hickling, Status review of initiation of environmentally assisted cracking and short crack growth. EPRI Palo Alto CA Technical report 1011788. (2005)

2. R.N. Parkins, Strain rate effects in stress corrosion cracking. Corrosion 46(3), 178 (1990)

3. R.N. Parkins, P.M. Singh, Stress corrosion crack coalescence. Corrosion 46(6), 485-499 (1990)

4. R.N. Parkins, E. Belhimer, W.K.J. Blanchard, Stress corrosion cracking characteristics of a range of pipeline steels in carbonate-bicarbonate solution. Corrosion 49(12), 951-966 (1993)

5. Y.-Z. Wang, K. Ebtehaj, D. Hardie, R.N. Parkins, The behaviour of multiple stress corrosion cracks in a Mn-Cr and Ni-Cr-Mo-V Steel-I-Metallography. Corros. Sci. 37(11), 1651-1675 (1995) 
6. Y.-Z. Wang, K. Ebtehaj, D. Hardie, R.N. Parkins, The behaviour of multiple stress corrosion cracks in a $\mathrm{Mn}-\mathrm{Cr}$ and a Ni-Cr-Mo-V steel: II-Statistical characterisation. Corros. Sci. 37 (11), 1677-1703 (1995)

7. Y.-Z. Wang, K. Ebtehaj, D. Hardie, R.N. Parkins, The behaviour of multiple stress corrosion cracks in a Mn-Cr and Ni-Cr-Mo-V Steel-III-Monte Carlo simulation. Corros. Sci. 37(11), 1705-1720 (1995)

8. Y. Ochi, A. Ishii, S.K. Sasaki, An experimental and statistical investigation of surface fatigue crack initiation and growth. Fatigue Fract. Eng. Mater. Struct. 8(4), 327-339 (1985)

9. O. Calonne, L. Fournier, P. Combrade, P.M. Scott, P.Chou, Experimental study of short crack coalescence in nickel-base alloys in PWR primary water. In Proceedings of the 15th International Conference on Environmental Degradation of Materials in Nuclear Power Systems-Water Reactors, (2011), pp. 1647-1664

10. P.J.E. Forsyth, A unified description of micro and macroscopic fatigue crack behaviour. Int. J. Fatigue 5(1), 3-14 (1983)

11. H. Schreier, J.-J. Orteu, M.A. Sutton, Image Correlation for Shape, Motion and Deformation Measurements (Springer, US, Boston, MA, 2009)

12. T.C. Chu, W.F. Ranson, M.A. Sutton, Applications of digital-image-correlation techniques to. Exp. Mech. 25(3), 232-244 (1985)

13. D.J. Wu, W.G. Mao, Y.C. Zhou, C. Lu, Digital image correlation approach to cracking and decohesion in a brittle coating/ductile substrate system. Appl. Surf. Sci. 257(14), 6040-6043 (2011)

14. J.R. Yates, M. Zanganeh, Y.H. Tai, Quantifying crack tip displacement fields with DIC. Eng. Fract. Mech. 77(11), 2063-2076 (2010)

15. J. Quinta Da Fonseca, P.M. Mummery, P.J. Withers, Full-field strain mapping by optical correlation of micrographs acquired during deformation. J. Microsc. 218(1), 9-21 (2005)

16. B. Pan, K. Qian, H. Xie, A. Asundi, Two-dimensional digital image correlation for in-plane displacement and strain measurement: a review. Meas. Sci. Technol. 20(6), 062001 (2009)

17. G. Crammond, S.W. Boyd, J.M. Dulieu-Barton, Speckle pattern quality assessment for digital image correlation. Opt. Lasers Eng. 51(12), 1368-1378 (2013)

18. J.S. Lyons, J. Liu, M.A. Sutton, High-temperature deformation measurements using digital-image correlation. Exp. Mech. 36(1), 64-70 (1996)

19. J. Li, A. Lau, A.S.L. Fok, Application of digital image correlation to full-field measurement of shrinkage strain of dental composites. J. Zhejiang Univ. Sci. A 14(1), 1-10 (2013)

20. A.B. Cook, J. Duff, N. Stevens, S. Lyon, A. Sherry, J. Marrow, Preliminary evaluation of digital image correlation for in-situ observation of low temperature atmospheric-induced chloride stress corrosion cracking in austenitic stainless steels. ECS Trans. 25(37), 119-132 (2010)

21. J.A. Duff, T.J. Marrow, In-situ observations of intergranular stress corrosion cracking. In ASME 2008 Pressure Vessels and Piping Conference, 2008, pp. 847-854, 2008

22. J. Kovac, C. Alaux, T.J. Marrow, E. Govekar, A. Legat, Correlations of electrochemical noise, acoustic emission and complementary monitoring techniques during intergranular stress-corrosion cracking of austenitic stainless steel. Corros. Sci. 52(6), 2015-2025 (2010)

23. A. Stratulat, J.A. Duff, T.J. Marrow, Grain boundary structure and intergranular stress corrosion crack initiation in high temperature water of a thermally sensitised austenitic stainless steel, observed in situ. Corros. Sci. 85, 428-435 (2014)

24. J.A. Duff, T.J. Marrow, In situ observation of short fatigue crack propagation in oxygenated water at elevated temperature and pressure. Corros. Sci. 68, 34-43 (2013)

25. B.K. Bay, Methods and applications of digital volume correlation. J. Strain Anal. Eng. Des. 43(8), 745-760 (2008)

26. J. Lachambre, J. Réthoré, A. Weck, J.-Y. Buffiere, Extraction of stress intensity factors for 3D small fatigue cracks using digital volume correlation and X-ray tomography. Int. J. Fatigue 71, 3-10 (2015) 
27. N. Limodin et al., Influence of closure on the 3D propagation of fatigue cracks in a nodular cast iron investigated by X-ray tomography and 3D volume correlation. Acta Mater. 58(8), 2957-2967 (2010)

28. A. King et al., Tomography and imaging at the PSICHE beam line of the SOLEIL synchrotron. Rev. Sci. Instrum. 87(9), 093704 (2016)

29. L. Salvo et al., X-ray micro-tomography an attractive characterisation technique in materials science. Nucl. Instrum. Methods Phys Res. Sect. B Beam Interact. Mater. At. 200, 273-286 (2003)

30. H. Toda et al., Assessment of the fatigue crack closure phenomenon in damage-tolerant aluminium alloy by in-situ high-resolution synchrotron X-ray microtomography. Philos. Mag. 83(21), 2429-2448 (2003)

31. P. Cloetens et al., Observation of microstructure and damage in materials by phase sensitive radiography and tomography. J. Appl. Phys. 81(9), 5878-5886 (1997)

32. J. Bolivar, M. Fregonèse, J. Rethoré, C. Duret-Thual, P. Combrade, Evaluation of multiple stress corrosion crack interactions by in-situ Digital Image Correlation, Corrosion Science (2017). http://dx.doi.org/10.1016/j.corsci.2017.09.001

33. J.E. Hack, G.R. Leverant, On the prediction of the surface crack opening displacement of a part through crack. Int. J. Fract. 16(1), R15-R18 (1980)

34. T.T. Nguyen, J. Yvonnet, Q.-Z. Zhu, M. Bornert, C. Chateau, A phase field method to simulate crack nucleation and propagation in strongly heterogeneous materials from direct imaging of their microstructure. Eng. Fract. Mech. 139, 18-39 (2015)

35. T.-T. Nguyen, J. Bolivar, J. Réthoré, M.-C. Baietto, M. Fregonese, A phase field method for modeling stress corrosion crack propagation in a nickel base alloy. Int. J. Solids Struct. 112, 65-82 (2017)

36. T.J. Marrow et al., High-resolution, in-situ, tomographic observations of stress corrosion cracking (Elsevier, New York, 2005)

37. L.K. Zhu, Y. Yan, J.X. Li, L.J. Qiao, A.A. Volinsky, Stress corrosion cracking under low stress: continuous or discontinuous cracks? Corros. Sci. 80, 350-358 (2014)

38. L.J. Qiao, K.W. Gao, A.A. Volinsky, X.Y. Li, Discontinuous surface cracks during stress corrosion cracking of stainless steel single crystal. Corros. Sci. 53(11), 3509-3514 (2011)

39. T.L. Burnett, N.J.H. Holroyd, G.M. Scamans, X. Zhou, G.E. Thompson, P.J. Withers, The role of crack branching in stress corrosion cracking of aluminium alloys. Corros. Rev. 33(6), (2015)

40. P.J. Withers, Fracture mechanics by three-dimensional crack-tip synchrotron X-ray microscopy. Philos. Trans. R. Soc. Math. Phys. Eng. Sci. 373(2036), 20130157 (2015) 